\title{
LAS HUELGAS DE JULIO DE 1918 POR LA JORNADA LABORAL DE OCHO HORAS
}

\section{THE STRIKES OF JULY 1918 FOR THE EIGHT-HOUR DAY}

\section{Francisco Javier Rojas Sandoval ${ }^{*}$}

\begin{abstract}
RESUMEN
El objetivo de este artículo es describir y analizar las huelgas que protagonizaron los oficiantes de la madera en la ciudad de San José en el mes de julio del año 1918, en las cuales se destacó la demanda por el establecimiento de la jornada laboral de ocho horas. Se utilizó la metodología propuesta por Eric Hobsbawn y George Rudé para analizar las características de los movimientos sociales, las cuales se han adaptado para realizar una especie de "anatomía" de las huelgas, utilizando las siguientes variables: 1) distribución espacial y temporal de la huelga, 2) agenda del conflicto, 3) composición social del movimiento, 4) métodos de organización y patrón de liderazgo, 5) actitud de los patronos y un balance del movimiento social. Las huelgas de julio de 1918 constituyen el primer movimiento social en la historia de Costa Rica en donde se luchó por la jornada laboral de 8 horas. A pesar de no alcanzar esta demanda en su momento, se logra colocar por primera vez en la palestra del conflicto social y de la agenda social la jornada laboral de ocho horas como un derecho de los trabajadores.
\end{abstract}

PALABRAS CLAVE: TRABAJADOR ESPECIALIZADO * TRABAJO * HISTORIA SOCIAL * HUELGA * DERECHO LABORAL

\section{ABSTRACT}

The objective of this article is to describe and analyze the strikes that led the wood officiants in the city of San José, in July 1918, in which the demand for the establishment of the eighthour workday was highlighted. The methodology proposed by Eric Hobsbawn and George Rudé was used to analyze the characteristics of the social movement, which have been adapted to perform a kind of "anatomy" of the strikes by using the following variables: 1) spatial and temporal distribution of the strike, 2) conflict agenda, 3) social composition of the movement, 4) organization methods and leadership pattern, 5) employers' attitude and a balance of the social movement. The strikes of July 1918 were the first social movement in the history of Costa Rica where they fought for the 8-hour workday. In spite of not reaching this demand at the time, they placed, for the first time, in the arena of the social conflict and the social agenda the eight-hour workday as workers' rights. 


\section{INTRODUCCIÓN}

En este artículo se analizan las huelgas que protagonizaron los trabajadores de la madera en la ciudad de San José, en el mes de julio del año 1918. Entre las demandas de los carpinteros y ebanistas destaca el establecimiento de la jornada laboral de ocho horas. La importancia histórica de este movimiento social en el proceso de formación de la clase trabajadora costarricense, es que constituye la primera huelga en la historia de esta población, en la cual se demandó el establecimiento de una jornada laboral de ocho horas, siendo el antecedente de la "marejada" de huelgas de febrero de 1920, que condujeron a la promulgación de la ley nro. 100 de diciembre de 1920, que emitió la legislación laboral que regula la jornada de trabajo.

El estudio de las huelgas está antecedido por la obra de Vladimir de la Cruz, Las luchas sociales en Costa Rica 1870-1930 (2004), quien señaló por primera vez la importancia de estudiar a las clases subalternas como objeto de investigación. El trabajo de Mario Oliva, Artesanos y Obreros Costarricenses 1880-1914 (2006) y de Víctor Hugo Acuña, Los orígenes de la clase obrera en Costa Rica: las huelgas de 1920 por la jornada de ocho horas (1986) abrieron una nueva perspectiva de la protesta social y de las huelgas en los procesos de formación de la clase obrera.

Para ello se procede a realizar una especie de "radiografía" de la huelga, en la cual se describen $y$ analizan las siguientes variables: 1) distribución espacial y temporal de la huelga, 2) agenda del conflicto, 3) composición social del movimiento, 4) métodos de organización y patrón de liderazgo, 5) actitud de los patronos y un balance del movimiento social.

A cien años de haber acontecido la primera huelga, donde se luchó por primera vez por una jornada laboral de ocho horas, esta pasa actualmente invisibilizada en la memoria, no solo de los sectores subalternos, sino también de la clase media, que vive a lo sumo del recuerdo de la época dorada del periodo del Estado Benefactor. En el ámbito de las ciencias sociales en general y de la Historia en particular, las temáticas referentes a la historia del trabajo y de los trabajadores, incluyendo desde luego sus luchas, han dejado de abordarse, ocupando una posición marginal a nivel historiográfico. En consecuencia, este trabajo pretende recuperar dicha temática investigativa en un momento en donde se celebra el 200 aniversario del nacimiento de Carlos Marx y su aporte a los estudios sobre el desarrollo del capitalismo y la teoría de la plusvalía, y en un contexto de globalización, en el cual la contradicción capital-trabajo no ha desaparecido, y lo que es más paradigmático, en la actualidad, para un contingente significativo de mano de obra descualificada, trabajar parece constituir un privilegio y no un sistema de explotación.

La utilización de los conceptos oficiantes, obreros y trabajadores responde a un doble proceso histórico, en primer lugar, hace referencia al proceso de proletarización a que están transitando los artesanos de la carpintería y la ebanistería; $y$ en segundo lugar, a la pericia artesanal que se requiere para ejercer dichos oficios, que constituye históricamente una forma de defensa ante los procesos de capitalización del oficio - introducción de maquinaria y energía moderna-.

El estudio de las huelgas se realizará desde el enfoque teórico de la historiografía marxista británica debido a su contribución al desarrollo de una historia desde abajo, que visualiza a las clases populares como agentes de la historia (Kaye, 1989). Los historiadores marxistas británicos no solo insisten en la importancia para los estudios históricos del estudio de las experiencias de las clases bajas, también insisten en que las clases bajas han sido participantes activos en la formación de la historia, más que meras víctimas pasivas. Finalmente, insisten en la importancia central de la lucha de clases en el proceso de formacion de clase.

\section{CARACTERIZACIÓN DE LAS HUELGAS}

El movimiento huelguista de los trabajadores de la madera en julio de 1918, estuvo precedido por una serie de estallidos huelguísticos previos. La Prensa Libre en su edición del 10 de julio de 1918, describió dicha marejada huelguista en los siguientes términos: "El movimiento huelguista que comenzó en San José el 
gremio de zapateros, propagándose enseguida a otros círculos tiende a ser general, $y$ decimos esto porque entre los empleados de comercio corre como válido el rumor de que en breve estallará entre ellos una huelga" (p. 3).

No se comparte el criterio del diario respecto a que dichas protestas sociales constituyeron un movimiento general, valga decir, una huelga general; no obstante, la nota periodística lleva a plantear las siguientes preguntas: ¿por qué el movimiento huelguista de julio de 1918 no fue exitoso en comparación con el escenificado en febrero de 1920?, ¿por qué los patronos se impusieron en el terreno de la confrontación social a los obreros de la madera en julio de 1918, en contraposición con lo acontecido en febrero de 1920?, ¿cómo valorar en perspectiva histórica las huelgas protagonizadas por los carpinteros y ebanistas, pese a haber conquistado solo el pago de horas extras?

La Primera Guerra Mundial, sin lugar a dudas, constituyó un factor que aumentó el alto costo de la vida y benefició al grupo de comerciantes. El corresponsal de La Prensa Libre, en la edición del 10 de julio, lo señaló en forma contundente: "Es creencia general, $y$ hasta se dice que bien fundada, la de que los dueños de tiendas, $y$ de comestibles son los únicos que han sacado ventajas de la situación económica y de la catástrofe europea" (1918, p. 1).

El estudio de dicho movimiento social de julio de 1918, pretende aportar no solo un conocimiento de la lucha emprendida por los carpinteros y ebanistas por un derecho fundamental para los trabajadores, sino también concientizar actualmente a la población trabajadora, $y$ en general, a los habitantes que pueblan Costa Rica, que nada se consigue en este mundo sino se lucha por ello.

\section{1) DISTRIBUCIÓN ESPACIAL Y TEMPORAL}

Las huelgas de julio de 1918 tuvieron una duración de cinco días, las cuales iniciaron el sábado 6 de julio de ese año. Al finalizar la jornada laboral de ese día, según reseñó el periódico La Información - periódico que apoyaba la dictadura de Federico Tinoco- los obreros carpinteros de la ciudad de San José, enviaron un memorial a todos los dueños de talleres, donde solicitaban un aumento de salario. El memorial fue remitido a los siguientes patronos: Luis Gomis, Salvador López, José Urgelles, Mariano Salazar, José Poch, Jorge Morales Bejarano, Forn y Costa, Mariano Struk, Faith y Co y Santos Penón (La Información, 07/07/1918).

La cadena de huelgas de julio de 1918 se desarrolló en la ciudad de San José, en las unidades productivas más capitalizadas de la época; en consecuencia, no tuvieron una proyección regional, como si aconteció en las huelgas de febrero de 1920. El movimiento huelguístico de julio de 1918 precede a la coyuntura huelguística de febrero de 1920, que llevaría a la aprobación de la Ley por la Jornada de Ocho Horas.

\section{2) AGENDA DEL CONFLICTO Y LAS DEMANDAS PLANTEADAS}

Las peticiones de los huelguistas son reveladoras de su condición socioeconómica como trabajadores proletarizados, dependientes de un sueldo o de un salario, en ese sentido, en las huelgas de julio de 1918, la petición salarial ocupó un lugar de primer orden, junto con el establecimiento de una jornada laboral de ocho horas $y$ el pago de horas extraordinarias. El aumento salarial demandado por los carpinteros y ebanistas hacia sus respectivos patronos fue de un $40 \%$.

La agenda del conflicto en julio de 1918 —al igual que en 1919 y en los primeros meses de 1920 - giraba en torno al problema de las subsistencias, es decir, el bajo monto de sus ingresos en relación con los precios de los artículos de primera necesidad. Esta primera oleada huelguística está marcada, sin lugar a dudas, por los efectos de la Primera Guerra Mundial. Dicha crisis afectó negativamente a los obreros urbanos, al disminuir las importaciones a causa del bloqueo de las comunicaciones, que redundó en escasez y carestía. En este contexto, los operarios de carpintería de San José le enviaron una circular a los patronos, en la cual les exponían el impacto de la Gran Guerra sobre su nivel de vida:

En las actuales circunstancias en que el mundo civilizado se encuentra comprometido en una espantosa guerra, en la 
que nosotros costarricenses, estamos también enrolados nos obliga a exponer lo que sigue: [...] la vida para el obrero se hace cada día más penosa, los víveres aumentan de día en día de un modo alarmante; de modo que pronto nos veremos todos en tal situación que ya la vida será imposible (La Información, 07/07/1918, p. 3).

De ahí que los carpinteros capitalinos - en un tono conciliador- justifiquen ante sus patronos, un aumento significativo de sus salarios, en razón del impacto de la Primera Guerra Mundial en la economía nacional. Los obreros que trabajaban en las carpinterías y ebanisterías de Luis Gomis, Salvador López, José Urgellés, Mariano Salazar, José Poch, Jorge Morales Bejarano, Forn y Costa, Mariano Struch, Fait y C. y Santos Penón, dirigieron a sus patronos un memorial, donde exponen las dificultades que atraviesan por la extraordinaria alza en los precios de los artículos de primera necesidad, demandando un aumento en sus salarios de un 40\% (La Verdad, 09/07/1918). La prensa de la época mostró solidaridad con el movimiento huelguista, por ejemplo, el periódico El Renacimiento, en su edición del 10 de julio de 1918, hace referencia al problema de las subsistencias al describir la carestía de víveres y su alto precio, justificando el movimiento de los trabajadores de la madera (El Renacimiento, 10/07/1918).

La importación de bienes de capital y materias primas alcanzaron un máximo en 1913, un año antes de que la Gran Guerra cortara el comercio y luego ambos bajaran hasta 1918 (León y Montero, 2016). Jorge León (2016) apunta que la reducción en materias primas fue menor que en bienes de capital, lo cual haría suponer que la producción industrial no cayó mucho con respecto al período inmediato anterior 1910-1913, excepto tal vez en el año 1918. Lo anterior vendría a explicar el pico de conflictividad social que se presenta hacia el final de la Primera Guerra Mundial en el mundo obreroartesanal. Carlos Hernández (1994) señala la existencia de seis huelgas en el año 1918, en los siguientes oficios de obreros:1) zapateros en Limón en el mes de junio, 2) zapateros en San
José en el mes de junio, 3) zapateros en Cartago en el mes de junio, 4) tipógrafos en San José en el mes de junio, 5) ebanistas en San José en el mes de julio, 6) pureras en San José en el mes de julio. El impacto de la Gran Guerra en el mundo obrero-artesanal se hizo sentir con más fuerza en 1918; de ahí que incluso un dueño de carpintería describiera en julio de ese año, las difíciles condiciones que estaban viviendo, al disminuir la demanda de muebles y aumentar el precio de los materiales:

No es cierto que nosotros hayamos subido el precio de las mercaderías; al contrario, por razón de poca demanda, han bajado de precio. En cambio, el precio de los materiales ha subido en esta proporción: cedro: precio antiguo: el pie cuadrado 18 céntimos; actual 25; caoba: precio antiguo 20 céntimos; actual 45 y 50;[...] clavos: antes 2 libras por 35 céntimos; ahora el triple de precio (La Información, 09/07/1918, p. 4).

El patrón de carpintería concluía que, en las actuales condiciones, el mueble fino constituía un artículo de lujo y se había producido una disminución significativa de las ventas. Lo anterior está relacionado con la disminución de las importaciones de energía fósil - lo que indudablemente aumentó los costos de transporte-; Frank Notten en un trabajo magistral, describe el impacto de la disminución de las importaciones de energía fósil en Costa Rica, a tal punto que recuperó su nivel prebélico hasta 1925 (ver Notten, 2012, pp. 358-359). Además, se debe tener presente que en Costa Rica fue donde más cayeron las importaciones de bienes de capital (hierro y acero): las importaciones de hierro y acero disminuyeron a un ritmo de $35,4 \%$ anual en el período 1913-1918 (Notten, 2012).

El aumento salarial solicitado por los operarios de carpintería y ebanistería fue uniforme para todos los trabajadores de la madera; no obstante, la existencia de distintos niveles de cualificación de los trabajadores de la madera $y$, en consecuencia, de su distinto nivel de salarios. Hacia fines del decenio de 1910, el mundo obrero-artesanal era un conglomerado 
muy heterogéneo, donde las diferencias se evidenciaban en distintos grados de cualificación (maestros, operarios y aprendices); de género (oficios más proletarizados como el de las pureras); $y$ nivel de proletarización (trabajadores en talleres artesanales, manufacturas y fábricas). El periódico La Información, en la pág. 4 de su edición del 9 de julio de 1918, describió los distintos jornales de los obreros de la carpintería, de acuerdo con su nivel de cualificación: los artistas (maestros) tres colones cincuenta céntimos y cuatro colones diarios; operarios corrientes, dos colones cincuenta céntimos; ayudantes (medio oficiales) un colón, setenta y cinco céntimos a dos colones; $y$ finalmente, en la escala más baja se encontraban los aprendices (medio ayudantes) quienes recibían un sueldo que fluctuaba entre un colón y un colón y cincuenta céntimos (La Información, 09/07/1918).

Los jornales de los obreros de carpintería no guardaban proporción con las exigencias de la carestía de vida; en un contexto donde la combinación del descenso de las importaciones con la subida del tipo de cambio, se tradujo en escasez y alzas de precios de los artículos de consumo popular (Acuña, 1986). Cuando Estados Unidos entró en la guerra, las importaciones de harina de trigo disminuyeron fuertemente; entre 1913 y 1918, las importaciones de harina de trigo y maíz cayeron fuertemente en Costa Rica en un 27, 9\% anual. Por otra parte, los precios de la harina habían subido a 173 doláres por tonelada en 1918, desde 43,2 doláres en 1913 (Notten, 2012).

El memorial de los oficiantes de la madera enviado a los dueños de carpinterías y ebanisterías de San José, describía la extraordinaria alza en los precios de los artículos de primera necesidad; de ahí su demanda de un incremento en sus salarios de un 40\% (La Verdad, 09/07/1918).

La otra demanda presente en la mayoría de las huelgas protagonizadas por los carpinteros y ebanistas, fue la referente a la jornada laboral de ocho horas ${ }^{1}$. En julio de 1918, los

$1 \quad$ Dicha demanda fue planteada en 7 de las 9 huelgas protagonizadas por los carpinteros y ebanistas entre 1910 y 1943. operarios de "talleres" de carpintería y ebanistería de San José, que se manifestaron en huelga, demandaron a sus respectivos patronos, una reducción de las horas de trabajo pasando de 9 horas y media a 8 horas diarias (La Verdad, 10/06/1918; El Renacimiento, 10/07/1918 y La Información, 11/07/1918). En un memorial publicado por La Prensa Libre (1918), los oficiantes del ramo de la ebanistería y la carpintería manifestaron lo siguiente: "Ofrecemos volver todos a los talleres desde mañana, si se nos reduce a ocho horas de trabajo diario $y$ por cada hora $y$ media de trabajo extraordinario se nos reconoce el 50 por ciento del salario corriente" (p. 3).

La reivindicación de la jornada laboral de ocho horas había penetrado hacía ya algún tiempo en los círculos laborales urbanos: fue discutida en el Congreso Obrero Centroamericano de 1911. Asimismo, en la celebración del 1 de mayo de 1913, Joaquín García Monge hizo referencia en su discurso a la importancia de las horas de descanso para los trabajadores centroamericanos:

Hagamos lo posible, pues, por engrandecer a Costa Rica, a Centro América, que es lo que tenemos a mano; que nuestro vecino tenga casa confortable, libro que leer, deleítes artísticos baratos en las horas de descanso [...] campos libres que recorrer en los días primaverales ${ }^{2}$ (Marín y Torres, 2015, p.311).

En 1914, el establecimiento de la jornada laboral de ocho horas fue exigida como amenaza de huelga por los obreros del Ferrocarril al Pacífico (Acuña, 1986); no obstante, será en las huelgas de julio de 1918, protagonizada por los carpinteros y ebanistas capitalinos, donde la demanda de la jornada de ocho horas fue enarbolada por primera vez en la historia de Costa Rica.

Dicha demanda laboral se contextualiza en el proceso de formación del capitalismo en el sector secundario de la economía; en ese

2 Discurso pronunciado en el Edificio Metálico el 1 de mayo de 1913 por García Monge. Véase: Marín Hernández y Torres Montiel, 2015, p. 311. 
sentido, es imperativo señalar que el fantasma de la proletarización ya había tocado las puertas de las casas de los carpinteros y ebanistas en forma alarmante a fines de la década de 1910 e inicios del decenio de 1920.

El proceso de capitalización de las distintas unidades productivas en las que laboraraban los trabajadores de la madera, hacia fines del decenio de $1910^{3}$, tiene su correlato en las condiciones laborales y en los niveles de vida: jornadas de trabajo de 10 o más horas, bajos salarios y accidentes laborales periódicos, la incorporación de la mano de obra femenina e infantil. Las jornadas laborales impuestas por los patronos a los trabajadores de la madera, constituyen un mecanismo de explotación capitalista en su primera fase, en lo que Carlos Marx denominó plusvalor absoluto: alargamiento de la jornada laboral para la extracción de plusvalor. Marx (1959) lo planteó en los siguientes términos:

La suma del trabajo necesario y el plustrabajo, de los dos períodos de tiempo durante los cuales el obrero produce el valor que repone su fuerza de trabajo y la plusvalía, forma la magnitud absoluta de su tiempo de trabajo, es decir, la jornada de trabajo (Marx, 2014, p. 206) ${ }^{4}$.

Hacia fines de la década de 1910, las jornadas laborales de los oficiantes de carpintería y ebanistería eran de 9 horas y media; no obstante, tal y como se analizará mas adelante, los dueños no estuvieron dispuestos a disminuir la jornada laboral.

Los obreros de la madera demandaban el pago de un $50 \%$ de las horas de trabajo extraordinario (La Verdad, 1918), lo que denota que es muy probable que las jornadas laborales

3 La propagación de manufacturas y fábricas en el paisaje josefino está relacionada con la expansión del mundo urbano, el surgimiento de ferreterías y la introducción de la electricidad en el ámbito del trabajo en el decenio de 1910, la inmigración de europeos y la tecnificación de los aserraderos. Véase al respecto: Rojas, 2014, p. 206.

4 La parte del producto en que se representa la plusvalía es lo que Marx denomino plus-producto. alcanzaran las 12 horas diarias, en períodos de alta demanda. La prensa de la época consideró justas las demandas esbozadas por los trabajadores del ramo de la carpintería y ebanistería. La Prensa Libre, en su edición del 9 de julio de 1918, en el titular "Se declararon en huelga los operarios de todos los talleres de carpintería", señaló lo siguiente:

Hoy por hoy el patrón está obligado a no dejarse para sí toda la ganancia. Debe hacer partícipe de ella a sus empleados, mientras pasa la amenaza del hambre, pues estando como están los artículos de primera necesidad a precios prohibitivos, no aumentar los salarios es provocar un estado de cosas más grave (p. 3 ).

\section{3) COMPOSICIÓN SOCIAL Y LÍDERES DEL MOVIMIENTO}

Las huelgas protagonizadas por los obreros de la madera entre 1910-1943, fueron escenificadas esencialmente por ebanistas; no obstante, en algunas participaron conjuntamente con los carpinteros en el escenario social, como aconteció en las huelgas de 1920, 1935 y 1943. En las huelgas de julio de 1918, las fuentes la consignan como una huelga de carpinteros; no obstante, al analizar las unidades productivas en donde se realizaron las protestas, resulta evidente la participación de obreros ebanistas. Las huelgas acontecieron en manufacturas y fábricas en proceso de capitalización desde mediados del decenio de 1910.

Estas unidades productivas se caracterizan por presentar dos denominadores; en primer lugar, la presencia de patronos extranjeros, esencialmente españoles, donde destacan las manufacturas y fábricas de muebles de José Urgelles, Santos Penón y Luis Gomis. En segundo lugar, por constituir las unidades productivas más capitalizadas de la época, donde la presencia de máquinas movidas por fuerza motriz, hidraúlica o eléctrica constituía una constante desde mediados del decenio de 1910.

En las huelgas de julio de 1918, se logra determinar la participación de 47 obreros del ramo de la ebanistería y la carpintería; entre los 
obreros localizados, se determinó la presencia de futuros dirigentes de la Sociedad de Ebanistas y Carpinteros; así como de otras organizaciones mutuales y sindicales: Guadalupe Borge, Gonzálo Hernández, José Baroni, Fabián Soto, Eduardo Llosent, José Maria Barquero, Miguel R. Povéda (La Información, 1918). Entre los socios fundadores de la Sociedad de Ebanistas y Carpinteros se identificó a Eduardo Llosent, primer presidente de dicha organización mutual. Asimismo, se encontraban Fabián Soto, Gonzálo Hernández y José Barquero, trabajadores proletarios, quienes laboraban hacia fines de la década de 1910 en los " talleres" más capitalizados de la época (La Prensa Libre, 07/07/1918). Hacia fines de la década de 1920, Gonzalo Hernández trabajaba por cuenta propia, en tanto que Fabián Soto y José Barquero continuaban siendo proletarios (Centro de Investigaciones Históricas de América Central, 1994b).

El movimiento huelguístico de julio de 1918 adquirió dimensiones importantes, si se considera que de las huelgas protagonizadas por los oficiantes de la madera entre 1910-1943 (de las que se tiene información sobre el número de huelguistas), la huelga de julio de 1918 fue la segunda con mayor participación, pues el número de huelguistas sobrepasó el centenar, según los reportes de la prensa (La Información, 10/07/1918).

En términos de composición social de este movimiento huelguístico, se concluye que los huelguistas son ebanistas y carpinteros de segundo y tercer orden (La Información, 11/07/1918), lo que denota, no solo su carácter proletario y obrero, sino también una categoría de cualificación del oficio de carácter intermedio a baja; lo anterior hacía que no fueran imprescindibles en el proceso productivo, de manera tal que su poder de negociación tendía a disminuir en un conflicto social, pues eran relativamente sustituibles.

\section{4) MÉTODOS DE ORGANIZACIÓN Y PATRÓN DE LIDERAZGO}

Las huelgas de julio de 1918 presentan dos características centrales; en primer lugar, constituyen una cadena de huelgas simultáneas y sucesivas que tuvieron un grado de vinculación y coordinación, pero que carecieron al inicio del movimiento de una dirección única y centralizada. En segundo lugar, si bien no contaron con una organización laboral que dirigiera la protesta social en su génesis, dicho movimiento social va a originar la constitución de la Sociedad de Ebanistas y Carpinteros en julio de 1918, organización que coordinó a partir de entonces dicha protesta social.

Los oficiantes de la madera capitalinos no contaban, al inicio de la huelga, con una organización laboral que velara por sus intereses; no obstante, dichos trabajadores actuaron en el escenario social de forma coordinada. Al respecto, llama la atención que en el inicio de este movimiento social, los obreros de la madera presentaran un memorial en forma conjunta a todos los dueños de talleres, el 6 de julio en horas de la noche (La Información, 07/07/1918).

En las huelgas de julio de 1918, la aptitud mostrada por los carpinteros y ebanistas fue la conciliación, así se lo hacen ver a los patronos al justificar sus demandas: "Nuestra petición, sin tomarlo de nuestra parte a protesta o rebelión, sino que la consideramos de justicia, creemos que ud. la considerará con benevolencia, y estará de acuerdo con nuestros deseos" ( $L a$ Información, 07/07/1918, p. 3).

La ideología de dichos actores sociales hacia fines del decenio de 1910, puede ser caracterizada como democrática y con algunas preocupaciones por la justicia social. Aunque en su discurso muestran una aptitud no confrontativa con los patronos, la realidad social es que recurrieron en forma conjunta a la lucha social en julio de 1918.

La estrategia seguida por los carpinteros y ebanistas de distintas manufacturas y fábricas - generalmente las más capitalizadas de la época - en ausencia de una organización laboral al inicio del movimiento, fue la de presentar en forma conjunta un memorial a los patronos (La Verdad, 09/07/1918). En el inicio de la huelga, los huelguistas se reunieron en el Centro la Juventud Obrera, ubicada 50 varas al sur del Balcón Europa, celebrando un mitín ( $L a$ Prensa Libre, 09/07/1918).

Las huelgas de julio de 1918 darán origen a la Sociedad de Ebanistas y Carpinteros, 
institución de clase fundada el 10 de julio de 1918, en la ciudad de San José, en medio de una huelga declarada por los trabajadores de la madera (Rojas, n.d, p. 131). En el acta de fundación de la citada organización de los oficiantes de la madera, se estipulan los objetivos de dicha institución:

Sociedad de Carpinteros Ebanistas se funda en la ciudad de San José, a las doce del 10 de julio de 1918, una Sociedad de Ebanistas Carpinteros con el propósito de trabajar en la organización del gremio, a fin de que este procure el mejoramiento de sus condiciones en todos los aspectos de su existencia ( $\mathrm{La}$ Información, 11/07/1918, p. 1).

La Sociedad de Ebanistas y Carpinteros, si bien constituyó una asociación de carácter mutual, en su actuación histórica cumplió funciones sindicales. El carácter mutual de dicha organización laboral obedece a que sus dirigentes fundadores son, en un porcentaje importante, artesanos acomodados e independientes $^{5}$. No obstante, la Sociedad de Ebanistas y Carpinteros va a adquirir funciones sindicales en el decenio de 1920, producto de dos factores: en primer lugar, su base social va a estar constituida por obreros proletarizados y artesanos en proceso de proletarización; en segundo lugar, su dirigencia va a estar constituida paulatinamente por obreros. En ese sentido, no deja de ser significativo que en la directiva elegida en febrero de 1921, se encuentren en la base de datos de 1927, a cinco empleados: Napoleón Flores (tesorero), Arturo Zuñiga (prosecretario), Rafael Salazar (vocal), José M. Barquero (vocal) y Miguel R. Póveda (vocal) (Centro de Investigaciones Históricas de América Central, 1994b y Diario del Comercio, 01/02/1921).

5 La primera junta directiva provisional de la Sociedad de Ebanistas y Carpinteros estuvo integrada por Eduardo Llosent, presidente; Epifanio Guila, secretario (dueño de una ebanistería); Juan Rafael Meneses secretario (dueño de una ebanistería) y Carlos Díaz, primer vocal (empleado). Véase: (Centro de Investigaciones Históricas de América Central, 1994b).
Resulta significativo señalar que en el proceso de negociación, los patronos negociaron con la recién constituida Sociedad de Ebanistas y Carpinteros, la finalización del conflicto (La Información, 10/07/1918). Aunque en este movimiento social privó la cordura y la negociación, la violencia no hizo acto de presencia en forma evidente, la prensa de la época reportó ligeros incidentes personales entre operarios, huelguistas y patronos (La Información, 11/07/1918). La historiografía costarricense ha descrito el mundo obrero-artesanal en una forma romántica: autodidactas, portadores de una ideología democrática y dispuestos a la negociación en el terreno de la confrontación social. Sin embargo, la violencia formó parte de las relaciones sociales, en ese sentido, el 03 de setiembre de 1918, La Prensa Libre describió una riña en un taller de carpintería:

Un aprendiz de carpintería hirió a Gustavo Reyes, operario que se había convertido en maestro del primero. Esto ocurrió en el taller donde ellos trabajan.

Parece que el maestro reprendió al discípulo por haber hecho mal el trabajo de una silla. [...] La disputa continuó y de un momento a otro, el aprendiz tomó un formón con el que infirió una herida en el brazo izquierdo al señor Reyes.

El filo del arma llegó hasta tocar el hueso y la herida tardará en sanar quince días. Hecho eso, el aprendiz huyó hacia su casa, pero horas más tarde fue detenido por la policía (p. 1).

Si bien, este podría ser un caso aislado, habría que tener presente que la prensa de la época describía los accidentes de trabajo en forma periódica. Lo anterior es un indicador indirecto de las condiciones de vida de los aprendices y de los obreros proletarizados, quienes no solamente debían trabajar jornadas de hasta 10 horas diarias, sino que recibían bajísimos salarios en comparación con los maestros, y en un contexto de crisis económica, en que el 
problema de las subsistencias probablemente adquirió dimensiones dramáticas para este tipo de oficiantes.

En el conflicto social de julio de 1918, las posiciones tanto de obreros carpinteros $y$ ebanistas, por un lado, y la de los dueños de carpinterías y ebanisterías, por otro lado, eran contrapuestas. El diario La Información en su edición del 11 de julio de 1918, lo describió en una forma muy objetiva:

Los empresarios boicoteados hacen notar la escasez de órdenes y los bajos precios a que venden los muebles considerados como artículos de lujo. Trabajar en está situación — dicen ellos- es perder. Los operarios huelguistas informan lo contrario. Esto es, dicen que a los patronos les sobran los encargos de muebles finos y que hacen magníficos negocios (p. 3).

A todas luces resultaba evidente la explotación a que estaban sometidos los oficiantes de la madera, debido a las largas jornadas y los bajos salarios, asimismo, por las condiciones de trabajo, donde los accidentes laborales - una temática que no ha sido abordada de forma sistemática por la historiografía costarricense- constituía un paso para transitar de la condición de proletario a la mendicidad, aparte del fantasma de la desocupación, que podía tocar sus puertas en un contexto de crisis económica.

\section{5) LA ACTITUD DE LOS PATRONOS Y BALANCE DE LAS HUELGAS}

Algunos patronos involucrados en el conflicto, excepcionalmente, no asumieron una postura intransigente hacia todas las demandas planteadas por los oficiantes de la madera $y$ fueron condescendientes con las solicitudes planteadas por los carpinteros y ebanistas - a excepción del establecimiento de la jornada laboral de 8 horas-. De esta forma, patronos como Mariano Struck, contestaron rápidamente a las demandas planteadas por los trabajadores de la madera. El 8 de julio - un día después de iniciado el movimiento- Struck contestó favorablemente a la demanda de aumento de salarios (La Información, 09/07/1918). Incluso algunos empresarios, como Jorge Morales Bejarano, se mostraron dispuestos a aceptar las demandas planteadas por los carpinteros y ebanistas, en los siguientes términos: "No por conveniencia, sino por sentimiento de justicia $y$ de equidad yo estoy listo a satisfacer las demandas de los huelguistas, siempre que sigan este mismo camino dos o tres empresarios más" (La Información, 10/07/1918, p. 3).

No obstante, algunos patronos fueron del todo reacios a las peticiones laborales, tal fue el caso de Luis Gomis, quien censuró a sus operarios por la actitud que habían tomado, lo que condujo al abandono de todos los trabajadores de su "taller" (La Información, 10/07/1918). La Prensa Libre en su edición del 9 de julio de 1918, describió en los siguientes términos, la aptitud asumida por el empresario Luis Gomis y el inicio de la huelga:

El señor Gomis se presentó mal humorado en su taller a las 9 de la mañana y parece que se dirigió a sus empleados en un tono poco conciliador, en consecuencia allí estalló primero la huelga. Vimos saliendo del taller a la hora indicada a los carpinteros cada uno con sus herramientas bajo el brazo (p. 3).

Un elemento importante de la descripción del diario, es la referente al proceso de trabajo, pues los carpinteros en este caso en particular, aportaban las herramientas. Lo anterior podría ser un indicador del grado de independencia que alcanzaron algunos carpinteros, ya que al disponer de sus propias herramientas, tenían en parte control del proceso productivo, en contraposición con los ebanistas.

La respuesta de los patronos en estas huelgas se dio de manera unificada, lo mismo que las demandas de los oficiantes de la madera, las cuales fueron planteadas en forma conjunta a los patronos de manufacturas y fábricas de San José. El 8 de julio se reunieron los patronos en el taller del español Luis Gomis con el objetivo de dar respuestas a las demandas de los trabajadores de la madera. 
En relación con la demanda de un aumento del $40 \%$ del salario para los trabajadores del ramo de la carpintería y la ebanistería, su primera respuesta fue negativa debido a lo inviable de dicha petición. En ese sentido, los patronos establecían una comparación con el último movimiento huelguístico de los zapateros, en donde las demandas planteadas por los oficiantes de zapatería, estipulaban un aumento salarial de un $25 \%$, en un oficio en donde la mercancía elaborada constituía un bien de primera necesidad, en oposición con los muebles, que en un contexto de crisis, representaban un artículo de lujo:

...en materia de negocios comerciales, nunca se puede comparar una industria con otra: la de fabricación de zapatos es muy superior a la de ebanistería. En tiempo de crisis, los buenos muebles se consideran artículo de lujo, en tanto que el zapato es prenda de uso obligatorio e inmediato... (La Información, 09/07/1918, p. 4).

No obstante, los patronos de carpinterías y ebanisterías consideraban justo y racional elevar los salarios de sus operarios, pero en una proporción relativa a las condiciones de sus negocios, que ellos calificaban de desfavorables en tiempos de crisis. La aptitud de los patronos en el conflicto social, fue la intransigencia, pues de las tres demandas planteadas por los trabajadores de la madera, solo accedieron al pago de cincuenta por ciento en las horas extraordinarias (La Verdad, 10/07/1918). Asimismo, propusieron un aumento de diez por ciento en los salarios, un porcentaje menor al logrado por los zapateros.

Finalmente, los dueños de manufacturas y fábricas se mostraron reacios a disminuir las horas de trabajo en las distintas unidades productivas; de ahí que las jornadas laborales en el resto del decenio de 1910 oscilaran entre 9 horas y media a las diez horas diarias. Incluso, los dueños de "talleres" advertían a sus operarios que quienes no regresaran a los talleres dentro de 24 horas, se considerarían cesantes, lo que evidencia la aptitud represiva asumida por los patronos. El 10 de julio de 1918, los empresarios José Poch, Salvador Lopez Luis Gomis, Feyth y Co, Forn y Costa, Manuel Salazar y José Urgelles enviaron un memorial al Presidente de la Sociedad de Ebanistería y Carpintería de la capital, en el que señalaban su propuesta ante las demandas planteadas por los trabajadores de la madera y les hacían un ultimatúm, en caso de rechazar la propuesta empresarial:

...lo menos oneroso para nosotros, y determinado conceder el $10 \%$ sobre los actuales salarios, mismas horas de trabajo y reconocer $50 \%$ de aumento sobre las horas extraordinarias que el patrón solicite al operario.

Queda entendido que concedemos hasta las 6 y 30 de la mañana del jueves 11 de corriente para la aceptación de nuestras concesiones, después de cuyo término y sin respuesta, consideraremos su intransigencia como rebeldía y anularemos las anteriores ofertas... (La Información, 10/07/1918, p. 1).

Ante la intransigencia de los patronos y la ausencia de una tradición organizativa hacia mediados de 1918 y en medio de una dictadura, los carpinteros y los ebanistas accedieron a la propuesta de los patronos. Los trabajadores de la madera se reunieron en los salones de la Juventud Obrera, el día 11 de julio y acordaron aceptar la resolución de los patronos, incorporándose a trabajar inmediatamente en las distintas unidades productivas, con lo cual llegó a su fin el movimiento huelguístico (La Información, 11/07/1918).

Al realizar un balance de las huelgas de julio de 1918, se debe señalar, en primera instancia, que fracasaron, puesto que de las tres demandas planteadas por los carpinteros y los ebanistas, los patronos solamente accedieron a una. No obstante, en perspectiva histórica, es decir de tiempo histórico, se debe concluir que las mismas fueron exitosas en la corta duración. En primer lugar, dicho movimiento huelguístico coloca por primera vez en la palestra del conflicto social $y$ de la agenda social 
en la historia de Costa Rica, la jornada laboral de ocho horas como un derecho de los trabajadores. En segundo lugar, durante el desarrollo de las huelgas, se constituye la Sociedad de Ebanistas y Carpinteros, institución de la clase trabajadora que tuvo una continuidad institucional entre 1918 y 1931. Recién terminada la huelga de los trabajadores de la madera, la Sociedad de Ebanistas y Carpinteros convocó a una reunión que se efectuó en los salones del Club Sport La Libertad, con el objetivo de nombrar la directiva en propiedad y de tratar de otros asuntos relacionados con la huelga ( $L a$ Prensa Libre, 13/07/ 1918).

Por último, no deja de ser significativo que en las huelgas por las jornadas de ocho horas de febrero de 1920, el movimiento social fuese iniciado por los carpinteros y los ebanistas de la ciudad capital. Efectivamente, el lunes 26 de enero de 1920 a las dos de la tarde, se congregó, en Asamblea General, la Sociedad de Ebanistas y Carpinteros de San José; en dicha reunión se formuló un pliego de demandas en el que se solicitaba a los patronos la implementación de la jornada laboral de ocho horas y un aumento de salarios del 20\%; por último, se fijó el 2 de febrero como fecha límite para recibir la respuesta patronal. El 2 de febrero de 1920 se declararon en huelga los trabajadores de los talleres de ebanistería y carpintería de la capital. Inmediatamente, se adhirieron al paro los albañiles y otros gremios josefinos.

\section{CONCLUSIONES}

Las huelgas de julio de 1918 se enmarcan en la transición del mutualismo al sindicalismo propiamente dicho; la huelga estudiada dio origen a la Sociedad de Ebanistas y Carpinteros, una organización mutual que cumpliría desde sus inicios funciones sindicales. Lo anterior es producto del proceso de proletarizacion que sufren los trabajadores de la madera a inicios del decenio de 1910 con la capitalización del oficio producto de la introducción de tecnología moderna en el proceso productivo. Lo anterior posibilitó que las dirigencias de las mutuales de los carpinteros y los ebanistas fueran ocupadas por proletarios y no por dueños de talleres como había acontecido hacia fines del siglo XIX $y$ principios del $\mathrm{xx}$, cuando surgen las organizaciones mutuales como una forma de defensa contra las adversidades, que buscan la protección del trabajador mediante la ayuda mutua sin pretender enfrentarse a los patronos $y$ al Estado en sus orígenes.

Conforme estos trabajadores se van proletarizando transitan hacia el sindicalismo, el punto culminante en el caso de los trabajadores de la madera lo constituye precisamente las huelgas de julio de 1918 .

A manera de hipotésis y de conclusión se podría plantear una continuidad entre las huelgas de julio de 1918, protagonizada por los obreros de la madera y las de febrero de 1920, iniciadas precisamente por la Sociedad de Ebanistas y Carpinteros. No obstante, surge una pregunta central: ¿por qué las huelgas de julio de 1918 no lograron una respuesta positiva a las demandas planteadas y las de febrero de 1920 resultaron exitosas? Probablemente, la respuesta haya que buscarla a nivel político y en el proceso de formación de la clase trabajadora. En ese sentido, el movimiento huelguístico de julio de 1918 no fue exitoso debido al ambiente represivo de la dictadura instaurada por los hermanos Tinoco y a la discontinuidad en el proceso de formación de la clase trabajadora, en lo referente a las instituciones de clase; es decir, hacia 1918, las distintas categorías de trabajadores urbanos no habían consolidado organizaciones laborales que tuvieran continuidad en el tiempo y cumplieran funciones más sindicales.

En contraposición, hacia febrero de 1920 , el proyecto hegemónico de la burguesía recién había sufrido un resquebrajamiento con la caída de la dictadura de los Tinoco. En este contexto, los grupos de trabajadores urbanos fueron protagonistas activos de los tumultos populares de repudio hacia la dictadura del 2 de setiembre de 1919, cuando asumió el poder el presidente provisional Francisco Aguilar Barquero. Por vez primera, las clases trabajadoras urbanas inclinaban significativamente la balanza en el juego de la política nacional. Su contribución a la restauración del régimen democrático costarricense, implicó la necesidad de atender sus reivindicaciones económicas y sociales, lo que explica en parte su éxito en las 
huelgas de febrero de 1920 (Acuña, 1986) . El otro factor de su triunfo en la arena social, fue el comportamiento como clase social de distintas categorías ocupacionales, a través de instituciones de clase consolidadas, las que pese a su carácter mutual cumplen funciones sindicales y su triunfo en el terreno de la arena social.

El problema de las subsistencias, los bajos salarios y las extensas jornadas de trabajo no fueron solucionados con las huelgas de los trabajadores de la madera de julio de 1918. Dichos problemas formaban parte de la agenda social de la clase trabajadora costarricense. La Prensa Libre en su edición del 23 de julio de 1918, describió la agenda del mitín de obreros que se iba a celebrar, en donde se destaca el problema de los bajos salarios, el alto costo de los artículos de primera necesidad, el desempleo y las jornadas de trabajo (La Prensa Libre, 23/07/1918).

La legislación social emitida durante la administración de Calderón Guardia se forjó bajo el yunque de la lucha de clases en el período previo a la promulgación de la Reforma Social y es producto de la lucha social llevada a cabo por la clase trabajadora, antes incluso de la fundación del Partido Comunista. En ese sentido, no resulta casual que la legislación en torno a la jornada laboral de ocho horas incorporada en el Código de Trabajo sea producto de la lucha social llevada a cabo por una serie de trabajadores urbanos desde fines del decenio de 1910 (al estallar las huelgas de julio de 1918, en donde precisamente los carpinteros y los ebanistas luchan por primera vez por el establecimiento de una jornada laboral de ocho horas) $y$ particularmente, durante las huelgas de febrero de 1920, que van a llevar a la promulgación de dicha legislación en diciembre de ese año. No obstante, entre hecho $y$ derecho existe una gran distancia, lo que llevó a su continuo incumplimiento por parte de los patronos, como lo sufrieron los trabajadores de carpintería y ebanistería, quienes precisamente entre 19201943, realizaron una serie de huelgas, donde la demanda central constituyó el cumplimiento de la Ley de Jornada Laboral de Ocho Horas.

Si bien, la ley que establece la jornada laboral de ocho horas es producto de la lucha de distintos actores sociales que actuaron separadamente, en las denominadas huelgas de febrero de 1920, la posterior lucha social por el cumplimiento de dicha legislación y su inclusión en el Código de Trabajo constituyó un legado de los carpinteros y de los ebanistas, lucha que inicia precisamente en julio de 1918.

La génesis de la ley de la Jornada de Ocho Horas hay que rastrearla, en última instancia, en los procesos de confrontacion social, valga decir, de la lucha de clases y de negociación de los actores sociales.

\section{REFERENCIAS}

Acuña Ortega, V. (1986). Los orígenes de la clase obrera en Costa Rica: Las huelgas de 1920 por la jornada de ocho horas. San José, Costa Rica: CENAP-CEPAS.

Centro de Investigaciones Históricas de América Central. (1994a). Base de datos computarizados de los cuatro distritos capitalinos. San José, Costa Rica.

Centro de Investigaciones Históricas de América Central. (1994b). Base de datos del Censo de Población de 1927. San José, Costa Rica: Universidad de Costa Rica.

De la Cruz, V. (1980). Las luchas sociales en Costa Rica 1870-1930. San José, Costa Rica: Editorial Costa Rica.

De lo que se tratara en el próximo mitin de obreros. (23/07/1918). La Prensa Libre, p. 3.

El conflicto entre carpinteros y patrones. (09/07/1918). La Información, p. 4.

El conflicto obrero del día. (10/07/1918). La Información, p. 3.

El movimiento huelguista de los obreros carpinteros quedó terminado: los huelguistas aceptaron lo propuesto por sus patrones. (11/07/1918). La Información, p. 1.

Fin de una Huelga. Hoy a medio día los ebanistas y carpinteros aceptaron las proposiciones de sus patrones. (10/07/1918). La Prensa Libre, p. 3

Hernández-Rodríguez, C. (1994). De la represion a las formulas de consenso: contribución al estado de la conflictividad huelguística costarricense (1900-1943) (Tesis de Licenciatura). Universidad Nacional, Heredia, Costa Rica. 
Hobsbawm, E., y Rudé, G. (1978). Revolución industrial y revuelta agraria. El Capitan Swing. Madrid, España: Siglo xxI Editores.

Huelga de carpinteros en la capital. (10/07/1918). El Renacimiento, p. 1.

Huelga. (10/07/1918). La Verdad (4), p. 4.

Kaye J. H.(1989). Los historiadores marxistas británicos. Un análisis introductorio. Zaragoza, Universidad de Zaragoza.

La huelga de carpinteros. La situación continúa siendo la misma. (11/07/1918). La Información, p. 1.

León-Sáenz, J. y Montero-Mora, A. (2016). Historia económica de Costa Rica en el siglo XX. San José, Costa Rica: Editorial de la Universidad de Costa Rica.

Manifestación a los operarios de ebanisterías y carpintería. (10/07/1918). La Información, p. 1.

Marín-Hernández, J. J. y Torres-Montiel, M. (2015). Musa Obrera: Historia, balances y desafíos de la clase trabajadora en el centenario del 1 de mayo en Costa Rica, 1913-2013. San José, Costa Rica: Vicerrectoria de Docencia-cIHAC.

Marx, C. (2014). El Capital (4 ed., Vol. I). Ciudad de México, México: Fondo de Cultura Económica.

Movimiento obrero josefino. La sociedad de Ebanistas y Carpinteros. (01/02/1921). Diario del Comercio, p. 3

Notten, F. (2012). La influencia de la Primera Guerra Mundial sobre las economías centroamericanas 1900-1929: Un enfoque desde el comercio exterior. San José, Costa Rica: Centro de Investigaciones Históricas de América Central.
Oliva Medina, M. (1985). Artesanos y Obreros costarricenses 1880-1914. San José, Costa Rica: Editorial Costa Rica.

Petición. (09/07/1918). La Verdad, p. 1.

Riña en un taller de carpintería. (03/09/1918). La Prensa Libre, p. 1.

Rojas Sandoval, F. J. (2014). De artesanos a proletarios: Carpinteros y ebanistas en Costa Rica 1840-1930. Alajuela, Costa Rica: Editorial Universidad Técnica Nacional.

Rojas Sandoval, F. J. (n.d). La cultura política de las clases trabajadoras urbanas de Costa Rica: El caso de los carpinteros y ebanistas (1890-1943). Revista de Historia,(46), 111-148.

Rudé, G. (1979). La multitud en la historia: los disturbios populares en Francia e Inglaterra 1730-1848. Madrid, España: Siglo xxi Editores.

Se declararon en Huelga los operarios de todos lo talleres de carpintería. (09/07/1918). La Prensa Libre, p. 3.

Se declararon en huelga los operarios de todos los talleres de carpintería. (09/07/1918). La Prensa Libre, p. 3.

Se reúnen los patrones de carpintería. (09/07/1918). La Información, p. 4.

Sociedad de Ebanistas y Carpinteros. (13/07/1918). La Prensa Libre, p. 2.

Un nuevo conflicto obrero. (07/07/1918). La Información, p. 3.

Fecha de ingreso: 21/06/2019 Fecha de aprobación: 03/10/2019 
